\title{
Má notícia para a história do teatro no Brasil
}

\author{
Bad news for the history \\ of Brazilian teatre
}

\section{José Celso Martinez Correa}

José Celso Martinez Correa

Zé Celso é ator, dramaturgo e encenador. Um dos fundadores do Teatro Oficina, dirige o grupo desde 1958.

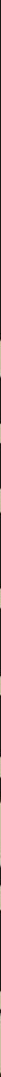


Regente dos coros do Teatro Oficina Uzina Uzona em direção à arte do teatro de estádio Oswald de Andrade. ${ }^{1}$

Achei muito estranho o fato de o Estadão estar demitindo a maior crítica de teatro do Brasil: Mariângela Alves de Lima.

Mais que amor à primeira vista, com Mariângela senti no nosso primeiro encontro, na cena, atuando em Gracias señor, a comunhão de uma irmã animal, que buscava naqueles tempos de escuridão, a luz onde quer que ela se encontrasse.

Aliás, o eterno Luis Antônio Martinez Corrêa, Luix, como pronunciam os meus irmãos, e entre eles o arquiteto João Batista Martinez Corrêa, são como ela, cancerianos, buscando sempre essa luz, que essa minha outra irmã, em seus territórios de ação, percebo neste instante que escrevo, busca.

Nosso esbarrão foi em 1972, no auge da repressão da ditadura militar, no teatro, no subterrâneo do Ruth Escobar.

Tinham acabado de arrancar os dentes dos ferros piramidais de $O$ balcão, de Vitor Garcia, e a arquiteta Lina Bo Bardi, criadora da arquitetura cênica de Gracias senõr, ou "Revolição - Lição de voltar a querer", foi comigo ver o espaço.

Lina pirou!

Não tinha mais poltronas! Nas paredes, tijolos quebrados, desvestidos da massa corrida, formavam uma caverna arruinada! Um paredão de pé-direito muito alto, pintado de negro, mas todo descascando!

Era exatamente o espaço cênico em que nós brasileiros, aquele ano, estávamos confinados, postos à força contra o paredão sem saída de fuga. Nossa geração nas prisões, torturados nos porões encobertos por cenografias

1 O texto foi publicado em 22 de dezembro de 2011 no Blog do Zé Celso. A resposta do editor do Caderno 2 de O Estado de S. Paulo, Ubiratan Brasil, foi a seguinte: "Adorei suas palavras sobre a Mariângela - concordo integralmente pois também sou um admirador de longa data do trabalho dela, imprescindível para a nossa cultura. Justamente por isso é que eu, como editor do C2, não seria (ou estaria) louco o suficiente para demiti-la. Infelizmente, Mariângela não quis ficar colaborando para o jornal sob uma nova filosofia de trabalho que, aliás, foi aceita por todos os outros colaboradores. Entendi perfeitamente, embora lamentasse muito. Mesmo assim, acertei que ela faça colaborações esporádicas, para não encerrar totalmente o vínculo. Gostaria que você também entendesse dessa forma. Esse episódio me deixou muito triste, especialmente por conta da reação das pessoas, indignadas (com razão) pela saída dela, mas, ao mesmo tempo, sem se preocupar em saber o que realmente aconteceu. Mariângela não foi demitida, volto a repetir. Apenas não julgou satisfatória a nova condição oferecida e preferiu sair. Beijo grande. Ubiratan" 
fakes de muros que escondiam as portas de entrada no inferno e nos sanatórios em que se lobotomizavam os dissidentes.

Lina imediatamente deslumbrada sacou: "Não precisa fazer nada. A arquitetura cênica do Gracias señor é esta, é o que a peça chama de TeAto, não mexam em nada!".

Em cena topei com Mariângela, na parte além da morte do desejo reprimido, na Barca de Serafim, no Sonho da União dos Corpos, na Orgya.

Senti que estava diante de uma sensitiva. Mariângela, uma jovem de 24 anos, estava em transe lúcido: tremia, tinha os olhos transbordantes d'águas e um vermelho vinho vibrava vivo em todo seu corpo.

Não estranhei nada quando, voltando do exílio, comecei a ler suas extraordinárias críticas no Estadão.

Lia a mesma sensitiva, com percepção aguçada do cerne do que via: do teatro em si ou não, de cada peça que observava.

Mariângela nunca julgou ou julga, nunca "prestou serviço" para os clientes do jornal, como todos os críticos da época, inclusive a velha senhora Bárbara Heliodora, a grande empregada dos valores do teatro pequeno burguês.

Mariângela ilumina com sua sabedoria sensível. Especifica o fenômeno teatral "em si", interpreta o que tem à sua frente, ilumina o trabalho dos artistas.

Depois de suas críticas os nossos trabalhos como que ganham a tão necessária percepção do outro, do artista, do público amante da arte em si.

Próximo a ela antes estava lan Michalski.

Ela retoma a tradição dos grandes críticos, como Décio de Almeida Prado, Sábato Magaldi, Paulo Francis, mas já sem a crença que o teatro brasileiro havia começado com Padre Anchieta.

Nunca foi fundamentalista do teatro realista, de costumes. Não é fundamentalista do realismo das peças para a classe média. Tem a paixão pela ressurreição do teatro como grande arte.

Será que foi demitida por estas qualidades de ser independente, não empregada do jornal e de grande parte dos leitores deste?

Mariângela é uma das raras artistas da crítica.

Ela, que foi ver todas as peças do Teatro Oficina Uzina Uzona a partir de Ham-let, coisa que os críticos que fazem parte do júri do Prêmio Shell e da 
APCT atualmente já não fazem. Viramos agora fantasmas, para estas pequenas mediocridades instituídas.

Nenhum crítico desses escreve mais sobre nosso trabalho, reconhecido mundialmente para a ressurreição do teatro.

Ela viu e vê tudo. O Estadão tem outro crítico, que revelou-se um puxa-saco da família Mesquita, querendo rebaixar o teatro antropofágico para exaltar a dramaturgia realista do maravilhoso diretor da EAD, Alfredo Mesquita.

Na Folha de São Paulo, Nelson de Sá, Sérgio Sálvia, Mario Vitor, que enobreceram lá a crítica, foram sucedidos por críticos empregadinhos do jornal, e sem cultura teatral nenhuma. Até a chegada do ótimo crítico Luiz Fernando Ramos.

Destes críticos ficamos com ele e Mariângela na ativa nestes últimos anos decisivos, em que apareceram companhias muito fortes em Sampa. Nem dá para citar nomes, é uma florada. O teatro vive um renascimento ignorado pelo mainstream do teatro de costumes, teatro pequeno burguês de autoajuda, boa consciência, careta.

Toda esta revolução subterrânea, que não sai nos grandes anúncios horrendos dos Guias, está sendo percebida pelo olhar vidente de Mariângela como pontos luminosos prestes a iluminarem juntos o Eterno Retorno do Poder do Teatro como Arte, em Sampa Paratodos! Percebeu até essa revolução numa peça do teatro comercial: a última peça dirigida por Monique Gardenberg. Mariângela fez uma crítica que me fez ver o que não pude ver por estar trabalhando nos mesmos dias. Vejo que ela vê a beleza que pode brotar até no mainstream global.

A escrita de sua crítica de Cacilda! - lembro-me de quando lemos parecia jorrar em cachoeiras infinitas sobre nós. Chorávamos rindo de alegria e beleza do texto. Se ela sente arte, ela multiplica em mais arte.

Interpreta em vez de julgar, que é o que o artista faz. Por exemplo: nos revelou na sua crítica da Macumba urbana antropófaga que já não somos mais vingativos como o jabuti, mas estamos em 2011 a acreditar nos sinais. Colhendo palavras do texto de Oswald fez perceber ao público e a nós mesmos os rumos atuais do Oficina Uzina Uzona.

A maioria dos nossos espetáculos ela foi ver duas, ou até três vezes, antes de sair a crítica. A da Macumba saiu no último dia da peça. Mas valeu pelo brilho poético do que percebe como arte. 
Neste dia o Teatro Oficina, no início da Macumba, estava lotado do lado de dentro, e fora estavam 400 pessoas.

Nós tiramos a peça de cartaz para reensaiar Bacantes, que faz o gran finale do "Ano do Brasil na Bélgica", em janeiro de 2012, mas vamos voltar depois do carnaval, com a crítica de Mariângela abrindo alas para as novas temporadas da Macumba. Como ela sempre demora para escrever a crítica de nossas macumbas, ficamos putos muitas vezes, mas quando chega, entendemos.

O tempo dela não é o do rebanho.

Mariângela é a crítica artista, o João Gilberto da crítica do teatro brasileiro. Só cria em seu tempo, não de encomenda. É vital para o Estadão dar espaço para esta crítica artista. Ela é como João. O que produz nas letras, no jornal, tem a mesma maravilha da visão divina do criador da batida da bossa nova.

Por que desperdiçar um ser desta dimensão?

Ela fora do jornal vai continuar escrevendo por ser mesmo uma compulsiva grande crítica de teatro, como Harold Bloom, lan Kott. Mas e nós que estamos criando o teatro de que a mentalidade pequeno burguesa do rebanho tem medo, não entende, nem quer entender? Como ficamos sem Mariângela num jornal da importância do Estadão?

E como fica o Estadão sem uma Artista desta vitalidade?!

Será um sintoma desta época que tem medo da arte, que só pensa no rebanho mercantil, que vai se drogar no teatro para ver de perto os artistas de TV? Que tem horror e ódio do teatro que fazemos? Que dão bandeiras até de artefobia, de oficinofobia?

É um fato histórico no teatro-arte brasileiro essa demissão de sua meIhor crítica. É mais que justo que seja revisto pela direção do jornal, ou assumido como uma submissão à pressão da mediocridade burra do público consumidor do mercado de produtos descartáveis.

Submissão aos moralistas, aos que não querem o teatro que toque nos tabus do desejo de todos nós bichos humanos, sem importar a classe social. Aos que não querem abandonar os privilégios de sua imagem, de seu padrão. Aos que não querem transfigurar-se com a arte libertária do teatro. Aos que mantêm os padrões de opressão ao bicho humano que sai do seu papel miserável na sociedade de espetáculo, em pleno desabamento. 
Eu gosto muito das páginas do Caderno 2. Adoro os dois críticos de cinema e o Quiroga me dá sempre toques necessários. O Loyola, o Jabor, o adorável Daniel Piza - apesar de nunca ter aparecido no Oficina e ter um certo preconceito comigo - e todo o "time" de craques como Antoninho Gonçalves, Roberto da Matta, João Ubaldo Ribeiro, Marcelo Rubens Paiva, Luis Fernando Veríssimo, Jota B. Medeiros (muito importante, nosso aliado), Ubiratan Brasil. Gosto da importância ganha pela música nas páginas, etc...etc...

Mas pergunto: por que fazer isto com o teatro? Com a arte teatral?

Ela está emergindo com muita força, vinda dos terremotos da era capitalista liberal, que nunca soube apreciar esta arte.

A arte que Mariângela cultiva, como a música de João, vem vindo, com a economia verde, saltando os obstáculos de sua chegada com a rapidez da internet.

Estadão, por Cacilda Becker! Não cometa esta injustiça contra as leis de Antígone, as leis transumanas que a arte de teatro há milênios cultiva para o não desaparecimento da espécie humana, em extinção na caretice do rebanho.

Autor convidado 